\title{
DIRECTIVITY-INDUCED PULSE-LIKE GROUND MOTIONS AND FRACTURE RISK OF PRE-NORTHRIDGE WELDED COLUMN SPLICES
}

\author{
Biao Song ${ }^{1}$, and Carmine Galasso ${ }^{1}$ \\ ${ }^{1}$ Department of Civil, Environmental \& Geomatic Engineering, University College London, London, UK
}

\begin{abstract}
SUMMARY
Recent worldwide earthquakes have emphasized the severe damage potential of pulse-like ground motions caused by forward directivity close to a fault rupture. We investigate the effect of such directivity-induced pulse-like ground motions on the fracture fragility and fracture risk of pre-Northridge welded column splices (WCSs) in near-fault regions. To this aim, incremental dynamic analysis (IDA) is employed to explicitly quantify the pulse effects on WCS stress demands. Two case-study nonlinear welded-steel-moment-resisting-frame (WSMRF) models featuring WCSs (i.e., 4- and 20-story) are developed and subjected to (1) a set of pulse-like ground motions with varying pulse periods; and (2) a suite of ordinary (i.e., non-pulse-like) ground motions. Fracture fragility curves for both ordinary and pulselike records are then derived from the IDA results. These are finally combined with state-of-the-art near-source probabilistic seismic hazard analysis (NS-PSHA) for a case-study scenario rupture and six representative near-fault sites to assess WCS fracture risk. Findings from the study highlight that directivity-induced pulse-like ground motions affect the estimated fracture fragility and potentially increase the fracture risk of pre-Northridge WCSs in near-fault regions. These findings can guide similar performance-based assessment exercises for WSMRF to inform, for instance, the planning and design of retrofitting strategies for those vulnerable connections in near-fault regions.
\end{abstract}

\section{KEYWORDS}

Pre-Northridge welded column splice; fracture fragility/risk; pulse-like ground-motions; NS-PSHA

\section{INTRODUCTION}

In near-fault regions, earthquake-induced ground motions are often characterized by a large-amplitude and longduration pulse in the first portion of the ground velocity time history; such a pulse is more commonly observed in the fault-normal orientation than the fault-parallel one. These pulse-like ground motions are caused primarily by forward directivity (e.g., Shahi and Baker ${ }^{[1]}$; $\operatorname{Singh}^{[2]}$ ), as sketched in Figure 1 for a simple case of an unilateral strike-slip fault: when the fault rupture propagates towards the site and the rupture velocity is close to the shear-wave velocity, a highamplitude pulse can be generated due to the constructive interference between the arrival of the seismic energy from the rupture and the seismic wave front ${ }^{[3]}$. Such a pulse has an occurrence probability that depends upon the site-tosource geometry (e.g., Iervolino and Cornell ${ }^{[4]}$ ), and a peculiar pulse period that may be modelled as a function of the earthquake magnitude (e.g., Chioccarelli and Iervolino ${ }^{[5]}$ ). These directivity-induced pulse-like ground motions recorded close to a fault rupture are distinct from the ordinary (i.e., non-pulse-like) ground motions. Moreover, they are unlikely to be observed at sites which are more than $10-15 \mathrm{~km}$ away from a fault rupture (i.e., they generally occur in the so called 'near-fault' or 'near-source' regions), because the effect of forward directivity dramatically decreases with the distance from the fault as seismic waves scatter ${ }^{[4]}$.

In several near-fault regions, particularly in the west coast of the United States, welded steel moment resisting frames (WSMRFs) are a common lateral-load resisting system for earthquake resistance. Within mid- to high-rise WSMRF structures, welded column splices (WCSs) are commonly used to address length/transportation constraints and/or downsizing of the column sections due to the changes in loading at higher stories of a structure ${ }^{[6]}$. Recent studies by the authors (e.g., Galasso et al. ${ }^{[7]}$; Song et al. ${ }^{[8]}$ ) have shown that the fracture risk of pre-Northridge WCSs subjected to ordinary ground motions is relatively high due to three main issues: (1) they utilized low-toughness welds (i.e., characterized by Charpy V-Notch, CVN, values between 6.8-13.6 $\mathrm{J}^{[9]}$, which are much lower than the code-specified value of $27 \mathrm{~J}$ at $-18^{\circ} \mathrm{C}^{[10]}$ ), resulting in significantly low fracture capacity; (2) they featured partial joint penetrations (PJP) welds with weld penetrations of around $50 \%$ of the thinner flange thickness of $\mathrm{WCSs}^{[11]}$, producing a cracklike flaw in the region of low material toughness (i.e., unfused weld root); (3) they are force-controlled connections and their fracture is dominated by the tensile stress (rather than the inelastic deformation) - the expected fracture stresses, roughly in the range of $60-180 \mathrm{MPa}^{[8]}$, are much lower than the flange yielding strength of $400 \mathrm{MPa}$ mandated by AISC 341-16 $6^{[10]}$. Given these issues, a refined probabilistic assessment of fracture demands and capacities of WCS connections in pre-Northridge WSMRFs is of primary importance in several earthquake-prone areas, particularly for 
the prioritization/planning and design of retrofitting strategies for those vulnerable connections; see Song et al. ${ }^{[8]}$ for a detailed discussion on these aspects.

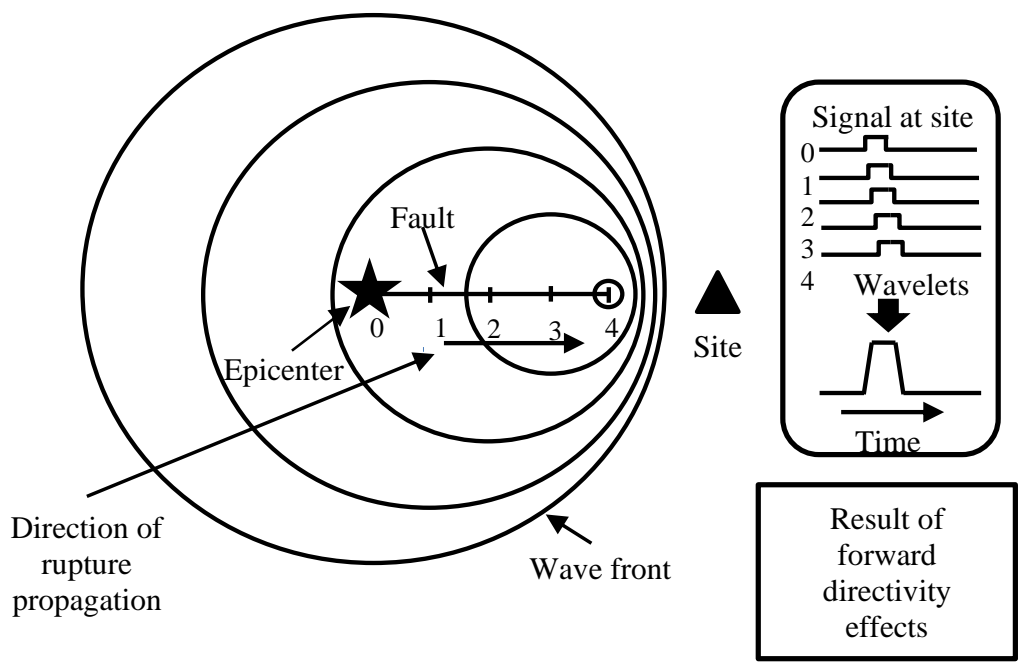

Figure 1 Schematic illustration of directivity effects on a site towards the direction of rupture propagation (adapted from Singh $^{[2]}$ )

The increased structural risk (particularly, collapse risk) due to near-fault, pulse-like ground motions has been highlighted by several recent earthquakes around the world, including the 1994 M6.7 Northridge, California, the 1995 M6.9 Kobe, Japan, the 1999 M7.6 Chi-Chi, Taiwan, the 2009 M6.3 L'Aquila, Italy, and the 2016-17 Central Italy sequence (featuring events in the magnitude range between 5.5 and 6.5), among others. These earthquakes have emphasized the higher damage potential of pulse-like ground motions, for instance in terms of larger elastic and inelastic displacement demands (e.g., maximum inter-story drift ratio, MIDR) compared to far-field, ordinary ground motions (e.g., Chioccarelli and Iervolino ${ }^{[5]}$ ). In the available literature published so far, most studies comparing structural demands to pulse-like and ordinary ground-motion records have focused on global deformations at (or near) the collapse limit state (e.g., Champion and Liel ${ }^{[12]}$; Tzimas et al. ${ }^{[13]}$ ). To the author's knowledge, local engineering demand parameters (EDPs), such as the stress demands, controlling the fracture of pre-Northridge WCSs, have not been properly investigated and quantified in the case of pulse-like ground-motion records. Reliable estimation of WCS fracture fragility and risk, particularly in near-fault regions, is critical and urgent, since: (1) given their structural function, the fracture risk of WCSs has major implications for occupant safety and thus, on decisions regarding retrofit; and (2) given their location, repair/retrofit of WCSs is costly and extremely disruptive to building operations. More in general, accurate evaluation of seismic fracture risk in the near-fault region is critical for the continued improvement of building code provisions.

Therefore, this study further investigates the fracture fragility and fracture risk of pre-Northridge WCSs in near-fault regions, particularly addressing the effect of pulse-like ground motions due to forward directivity on the distribution/increase of WCS stress demands (denoted as $\sigma_{D}$ ). To this aim, highly-detailed nonlinear finite element (FE) models are developed in OpenSees ${ }^{[14]}$ for two case-study index buildings, i.e., a 4- and a 20-story WSMRFs featuring WCSs (Section 2). A first record set, consisting of 91 near-fault, pulse-like ground motions with varying pulse periods (denoted as $T_{p}$ ), is used as input for incremental dynamic analysis (IDA ${ }^{[15]}$ ). The fracture capacity (denoted as $\sigma_{C}$ ) of the considered WCSs is computed through a simplified fracture mechanics-based approach derived by Stillmaker et al. ${ }^{[16]}$, also accounting for both aleatory and epistemic uncertainty affecting WCS fracture capacity. Fracture fragility curves (for ordinary records) and the ground-motion intensity values leading to fracture as a function of $T_{p}$ (for pulse-like records) are derived from the IDA results (Section 3). These are then combined with state-of-

the-art near-source probabilistic seismic hazard analysis (NS-PSHA) models accounting for forward directivity for a case-study scenario rupture. Six near-fault sites are considered to represent variations in site-to-source geometry and investigate the sensitivity of fracture risk to source-to-site distance. Following this, earthquake-induced fracture risk 
of pre-Northridge WCSs in the near-fault region is assessed and the results are critically discussed (Section 4). Finally, findings from this study are summarized (Section 5).

\section{BUILDING MODELS AND GROUND-MOTION SETS}

\subsection{Nonlinear Case-Study Models}

Two generic WSMRFs (i.e., 4- and 20-story frames), schematically illustrated in Figure 2, are simulated in this study to characterize the WCS stress demands. In particular, two representative WCSs, namely, splice \#1 and splice \#2 in these two frames (also indicated in Figure 2) have been selected, using a similar approach to that of Galasso et al. ${ }^{[7]}$, i.e., the selected splice flanges are characterized by the maximum stress level (among all splice flanges in the given buildings) at the 10/50 stress-hazard level. The aim is to illustrate the representative effect of pulse-like ground motions and the variation in response because of differences in building/splice properties. Both frames are similar to those used by Shaw et al. ${ }^{[6]}$, Galasso et al. ${ }^{[7]}$, and recently by Song et al. ${ }^{[8]}$. They are designed based on the SAC Steel Project models ${ }^{[17]}$, considering the same layout in both floor plans and elevations. However, as in Shen et al. ${ }^{[18]}$, the 3 -story SAC building model is replaced by a 4-story building to allow the presence of WCSs. This is because column splices are not commonly used in low-rise buildings with less than four stories. Figure 2 also shows the locations of the WCSs in each case-study frame. At each spliced level (indicated by block arrows in Figure 2), the WCSs are located $1.2 \mathrm{~m}$ above the lower story beams (measured from their top surfaces). This is typically the minimum distance required as per AISC 341-10 ${ }^{[19]}$, with the presumption that first mode response of the building will cause the doublecurvature bending of columns (i.e., maximum moments at two ends of the column with an inflection point at the midstory height). To represent the least conservative scenario according to the current design practice, the minimum required distance of WCSs is considered here. As shown in Figure 2, the 4-story frame is assumed to be spliced every two stories, while the 20-story frame is spliced every three floors. The WSMRFs are designed as per ASCE 7-05 ${ }^{[20]}$ and AISC 341-10, assuming they are designed for seismic hazard levels typical of the Los Angeles region in California, and firm soil conditions (i.e., Site Class D of NEHRP - National Earthquake Hazards Reduction Program). The fundamental periods (denoted as $T_{1}$ ) of these 4- and 20-story frames are $0.94 \mathrm{~s}$ and $2.36 \mathrm{~s}$, respectively. Further details of the building design and modeling approaches can be found in Shaw ${ }^{[21]}$ and Shaw et al. ${ }^{[6]}$. It is important to point out here that, despite being designed as per codes and standards issued after the Northridge earthquake, the stress demands in the splices are in line with those obtained from pre-Northridge frames. As reported by Gupta and Krawinkler ${ }^{[17]}$ based on extensive time history simulations, the major difference between the pre- and post-Northridge frames arise mainly from the local moment distribution in the beam-column connections. This is due to design detailing recommended in the new codes/standards, such as the introduction of reduced beam sections or flange reinforcements. In fact, their findings indicated that the global response and member force demands are almost identical between pre- and post-Northridge frames, if they were designed for the same conditions. As a result, it is assumed here that the WCS stress demands used in this study (to follow) are fair representations of those in preNorthridge frames.

OpenSees ${ }^{[14]}$ is used to simulate both frames and various physical features of the specific model response are considered. Specifically, in order to represent axial force-moment interaction and to spread plasticity in all beams and columns, force-based fiber sections ${ }^{[22]}$ are used for all structural elements. Theses fiber sections can provide direct examinations of tensile stresses within the cross sections. A bilinear steel hardening model of fiber section is utilized to define the steel material property under cyclic loading. Based on a database of plastic hinge response compiled by Lignos et al. ${ }^{[23]}$, the values of material parameters are calibrated as follow: the elastic modulus $(E)$ is equal to $2.0 \times 10^{5}$ $\mathrm{MPa}$, the yield strength $\left(F_{y}\right)$ is equal to $380 \mathrm{MPa}$ and the hardening slope is assumed equal to $5 \%$ of the initial elastic modulus.

It is worth noting that the selected constitutive model does not represent effective softening or deterioration due to effects such as local, lateral-torsional buckling and/or other instabilities. Although representation of such softening is crucial for simulating global instabilities such as collapse, it is of relatively modest significance here to deduce stress demands of WCSs. In fact, fracture risk of WCSs is dominated by low- to medium- intensity ground shaking at which building deformations (roughly to median MIDRs of about 3\% ${ }^{[7]}$ ) are well below the threshold above which these types of softening may occur (e.g., Lignos and Krawinkler ${ }^{[24]}$ ). This effect, noted previously by Galasso et al. ${ }^{[7]}$, is attributed to the saturation of stresses in WCSs (that are physically force-controlled) at relatively low levels of hazard, owing to yielding in other (deformation-controlled) elements of the structure (e.g., beams). As a result, strength loss and component deterioration are not modeled here as this study aims at quantifying earthquake-induced stress demands 
in WCSs, rather than predicting global collapse of the considered frames. Moreover, finite joint sizes are also modeled as additional fiber elements to control the locations of plastic hinge formations and panel zones. Geometric nonlinearity, known as $P-\delta$ (member) and $P-\Delta$ (story) effects, are simulated using geometric transformations. A leaning column is also added in each model to capture the destabilizing effects of vertical forces on the gravity frames.
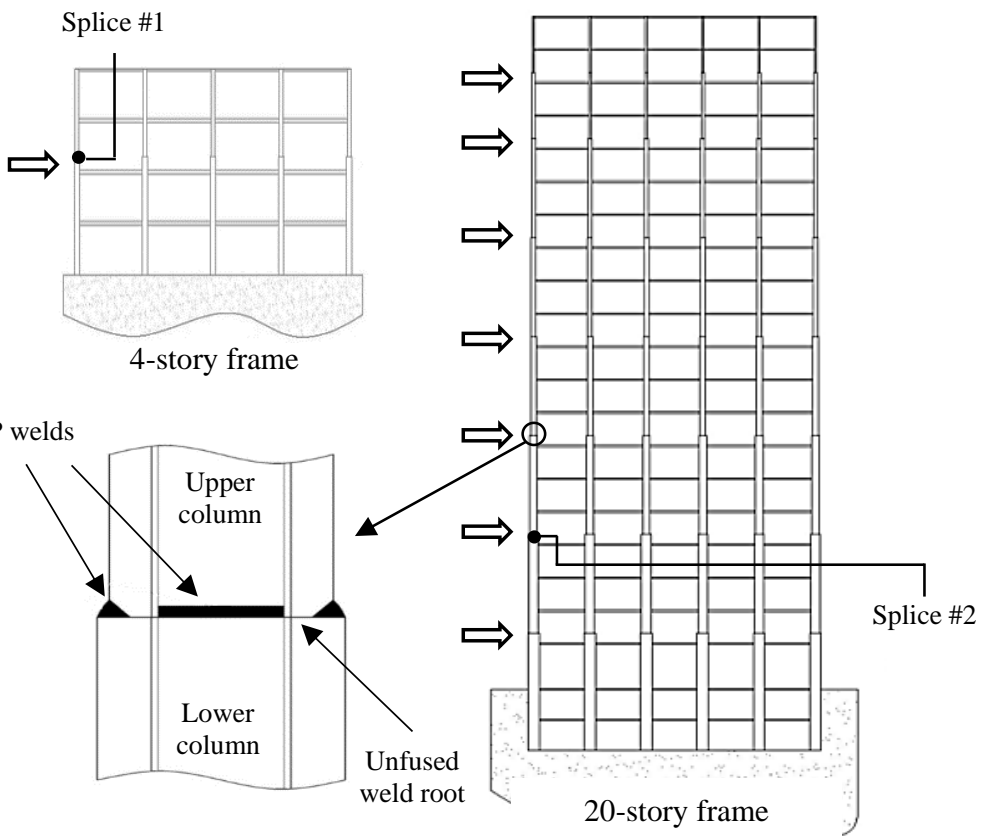

Figure 2 Schematic illustration of the pre-Northridge 4-story and 20-story WSMRF models, WCS levels (indicated by block arrows)/details and the locations of two representative WCSs.

It is finally worth noting that fracture propagation is not simulated in this study, whose primary focus is to characterize WCS stress demands from the perspective of informing the need for retrofit at a component level, considering the initial fracture of the WCS as the critical event controlling retrofit decisions. Nonetheless, propagation of fracture and its effect on WSMRF response is critical for a more holistic development of retrofit strategies. This has been conducted/addressed in a related article (i.e., Stillmaker et al. ${ }^{[25]}$ ), in which a special material model was developed in OpenSees ${ }^{[14]}$ to represent flange fracture.

\subsection{Ground Motion Datasets}

The fracture risk of WCSs depends on the fracture probabilities (i.e., fracture fragility) quantified from pulse-like and ordinary ground motions and their probabilities of occurrence (i.e., the seismic hazard at a given site); a detailed description of the probabilistic framework employed in this study is provided in Section 4. Furthermore, this study also aims to compare the earthquake-induced fracture fragility/risk at near-fault sites featuring pulse-like ground motions with that at far-field sites that are not affected by forward directivity effects. Therefore, two sets of ground motions, made by pulse-like and ordinary records respectively, are utilized here.

Specifically, a first set consisting of 91 pulse-like ground motions is employed as input for nonlinear dynamic analysis. This ground-motion set was compiled by Baker ${ }^{[26]}$ by using records from the Next Generation Attenuation (NGA) database developed by the Pacific Earthquake Engineering Research (PEER) Center. All the records in the considered set have been rotated to the fault-normal direction. The pulse periods of these records, ranging from $0.4 \mathrm{~s}$ to $12.9 \mathrm{~s}$, were detected and quantified through wavelet analysis, and the associated peak ground velocities are greater than 30 $\mathrm{cm} / \mathrm{s}$. The full list of this set can be found in Baker ${ }^{[26]}$. The moment magnitudes (denoted as $M$ ) of these records vary between 5.0 and 7.6. It is worth noting that the site-to-source distance (denoted as $R$ ) was not considered as a selection criterion, and therefore, it ranges from 0.10 to $102 \mathrm{~km}$. However, all the records show velocity pulses early in the time histories; some of the identified pulses may be generated by other seismic site effects, such as the sedimentary basin effect, rather than the near-fault directivity. However, due to the limited number of available pulse-record in empirical 
databases, all the 91 records in the set are considered in this study to make the pulse-like ground-motion set, with the assumption that the large velocity pulses due to different geological mechanisms will induce similar structural demands/effects. It should be acknowledged that, although some other researchers have assembled datasets of pulselike records (e.g., Mavroeidis and Papageorgiou ${ }^{[27]}$; Somerville ${ }^{[28]}$ ), also considering pulses at arbitrary orientations (not just the fault-normal one) in multicomponent ground motions ${ }^{[29]}$, this ground motion set is employed here as (1) the wavelet-analysis approach is quantitative, systematic and therefore easily reproducible for pulse identification ${ }^{\text {[12]; }}$ (2) the same datasets has been used by similar studies investigating different structural types and limit states (e.g., Champion and $\mathrm{Liel}^{[12]}$, for assessing the effect of near-fault directivity on reinforced concrete building seismic collapse risk; Tzimas et al. ${ }^{[13]}$, for assessing collapse risk and residual drift performance of steel buildings using post-tensioned MRFs and viscous dampers in near-fault regions).

A second set of records is used in this study to represent ordinary ground motions. They are part of the Federal Emergency Management Agency (FEMA) P695 far-field record set ${ }^{[30]}$, which contains 22 record pairs, each with two horizontal components (i.e., 44 records in total). Initially, nine of these records were removed from the considered set, because they exhibit pulses in velocity time history based on the wavelet classification algorithm results ${ }^{[12]}$. Moreover, for each pair of ground motions, only the component characterized by the larger peak ground acceleration (PGA) value is arbitrarily selected to reduce the computational burden (yet maintaining a statistically significant number of records for the analysis). A set of 21 records is finally used to represent generic far-field, ordinary ground motions in this study. These ground motions were recorded at sites no less than $10 \mathrm{~km}$ away from the fault rupture and their moment magnitudes range from 6.5 to 7.6. The selected far-field ground motion set used here is structure-type (i.e., period) and site-hazard independent as no specific spectral shape (and corresponding period range) was considered in the record selection. However, similar to the findings from Baker and Cornell ${ }^{[31]}$ and Champion and Liel ${ }^{[12]}$ for collapse risk assessment, a significant impact caused by spectral shape on the fracture risk assessment (e.g., with respect to relevant fracture fragility curves) has been observed by the authors. Therefore, the spectral-shape adjustment recommendations by Haselton et al. ${ }^{[32]}$ are applied here to account for the specific spectral shape of the far-field ground motions. This aspect is further discussed in Section 3.1.

\section{FRACTURE EVALUATION APPROACH}

As discussed above, fracture risk of each case-study WSMRF/WCS is evaluated through IDA ${ }^{[15]}$, which is suitable for performing probability-based seismic demand assessment for a wide range of seismic hazard intensities. In IDA, the numerical building model is subjected to a selected earthquake record while tracking the response of the structure (e.g., story displacements, floor accelerations, etc.). Each input ground motion (in each ground-motion set described in Section 2.2) is scaled in amplitude to increasing levels of intensity until fracture occurs (in the selected WCSs). This process is repeated for all earthquake records and for each frame/WCS connection. In this study, the considered ground-motion intensity measure (IM) for the scaling is the 5\%-damped spectral acceleration at the fundamental period of each case-study WSMRF, denoted as $S_{a}\left(T_{1}\right)$ (simply $S_{a}$ hereinafter). As discussed in Song et al. ${ }^{[8]}$, more advanced, spectral-shape-based IMs are generally recognized as better proxies for probabilistic seismic demand analysis of WCSs in terms of MIDR and $\sigma_{D}$, as they are usually characterized by higher efficiency and relative sufficiency compared with $S_{a}$. However, the use of such advanced IMs, particularly when performing site-specific PSHA, would require cross-IM correlation models that are explicitly developed for pulse-like ground motions. To our knowledge, there are no such models explicitly accounting for pulse-like ground motions. From a more general perspective, as discussed in detailed in Kazantzi and Vamvatsikos ${ }^{[33]}$, within a risk assessment framework, the reduction in response dispersion gained by a more efficient IM, does not reduce the overall risk variability: part of the variability is simply shifted to a different level within the risk assessment, and in particular to the seismic hazard curve definition. Thus, given the final aim of this study (e.g., quantifying WCS fracture risk in near-fault conditions), the use of $S_{a}$, for which various PSHA models/approaches - also including near-source effects - have been developed, seems appropriate.

The monitored demand parameter (i.e., the selected EDP) is the peak tensile stress $\left(\sigma_{D}\right)$ in the flange of the selected WCSs. Fracture occurs when $\sigma_{D}$ exceeds the stress capacity $\left(\sigma_{C}\right.$ ) for the WCSs of interest (i.e., splice \#1 and splice \#2 in this study, see Figure 2). To determine $\sigma_{C}$, analytical equations based on a fracture mechanics-based approach proposed by Stillmaker et al. ${ }^{[16]}$ are adopted. Specifically, the stress capacity of the selected WCSs is a function of the initial crack length $(a)$, the upper and lower WCS flange thickness ( $t_{\text {upper }}$ and $t_{\text {lower }}$ ) and the fracture toughness of 
the welded material (e.g., CVN value). The nominal values of flange thicknesses of splice \#1 (upper column section: W14×257; lower column section: W14×342) and splice \#2 (upper column section: W24×250; lower column section: W24×306) are given in Shaw ${ }^{[21]}$. For the pre-Northridge era, the initial crack length of WCS is assumed as half of $t_{\text {upper }}{ }^{[11]}$ and a typical value of CVN toughness is assigned as $13.6 \mathrm{~J}^{[9]}$. Following these specifications, the mean (deterministic) values of the fracture capacity for splices \#1 (4-story) and \#2 (20-story) are calculated as $113.6 \mathrm{MPa}$ and 108.2 $\mathrm{MPa}$, respectively. It should be noted that the uncertainty in the computation of $\sigma_{C}$ can be quite

significant ${ }^{[8,16]}$; therefore, a more conservative value (instead of the mean value) should be considered as nominal WCS stress capacity, particularly at the design stage.

Additionally, the maximum peak inter-story drift ratio (i.e., MIDR) is also recorded for each model and each groundmotion record. All the observed results show that the fracture criterion (i.e., $\sigma_{D}>\sigma_{C}$ ) is always violated at low $S_{a}$ levels, before the observed MIDR values reach a conventional 10\%-threshold for global collapse (or any numerical dynamic instability is noted). Consequently, it is assumed that there is no need to account for global collapse cases in estimating seismic fracture.

Statistics from the IDA results are used to derive fracture fragility relationships, defining the probability of fracture as a function of the hazard intensity. Such fracture fragility curves are defined by the median (denoted as $\mu$ ) and standard deviation (denoted as $\beta$ ) of the ground-motion spectral intensities at which fracture occurs in the IDA (named as fracture $S_{a}\left(T_{1}\right)$ in the following sections), assuming a lognormal distribution. The computed $\beta$-values provide a direct measure of the dispersion in the analysis results; such a dispersion is the results of the variability in ground motion characteristics. Capacity uncertainty, as discussed above (and in greater details in Song et al..$^{[8]}$ ), is especially important for predicting WCS fracture. For the analysis results provided herein, the record-to-record (aleatory) variability and the capacity (aleatory and epistemic) variability are assumed to be lognormally distributed and independent, such that the total variability is given by the square root of the sum of the squares. In particular, as demonstrated by Song et al. ${ }^{[8]}$, uncertainty in $\sigma_{C}$ leads to a $10 \%$ increase in the computed $\beta$ values (due to record-torecord variability) for WCS fracture; this value is, therefore, assumed in this study. A number of researchers are also working to improve predictions of modeling uncertainties for different types of structures, including WSMRFs. These estimates of modeling variability would change the absolute value of the fracture risk assessments but would not significantly affect the relative comparison among different buildings and sites.

\subsection{Fracture Evaluation under Ordinary Records}

As mentioned in Section 2.2, the records from the far-field ground-motion set (i.e., the ordinary records) were selected without any consideration of spectral shape (for a target site). Therefore, a scaled record may not have similar spectralshape features as a large, rare ground motion ${ }^{[34]}$, and scaling of records in this set may introduce a bias in the fracture assessment results. To measure the distinct spectral shape of a given ground motion, the parameter epsilon (denoted as $\varepsilon$ ), has been proposed by Baker and Cornel[ ${ }^{[35]}$. Specifically, $\varepsilon$ is defined as the number of logarithmic standard deviations between the observed spectral acceleration value (of a given record) and the median value estimated from a ground-motion model (GMM) for a specified structural period, earthquake magnitude, site-to-source distance, fault type, etc. Given the fact that the ordinary ground-motion set used in this study is approximately epsilon-neutral ${ }^{[32]}$, and the large and rare records (i.e., at low mean annual frequency of exceedance) are all positive-epsilon ${ }^{[35]}$, the practice of scaling up those records to represent severe ground motions for which there is a limited number of empirical data may result in an over-estimation of the WCS stress demands on the assessed frames ${ }^{[35]}$. This kind of bias may finally lead to an over-estimation of fracture fragility/risk of pre-Northridge WCSs.

To eliminate such biases from the ground-motion scaling, both ground-motion intensity (i.e., $S_{a}$ ) and $\varepsilon$ should be accounted for properly. In this study, the simplified method proposed by Haselton et al. ${ }^{[32]}$ is employed. Following this approach, the resulting fracture fragility curves for ordinary ground motions can be adjusted to consider the spectral shape effects that are not reflected in the considered record selection. In particular, the GMM developed by Boore and Atkinson ${ }^{[36]}$ is adopted here to predict the median values of $S_{a}$ for an assumed rupture/site scenario. Examples of such an $\varepsilon$ adjustment for the fracture fragility curves of the 4-story frame ( $\left.T_{1}=0.94 \mathrm{~s}\right)$ and the 20-story frame ( $T_{1}=2.36 \mathrm{~s}$ ) are shown in Figure 3, assuming a far-field strike-slip (SS) earthquake with moment magnitude of $M=7$, Joyner-Boore distance of $R_{J B}=50 \mathrm{~km}$, and a value of averaged shear wave velocity over top $30 \mathrm{~m}$ 
(denoted as $V_{s, 30}$ ) as $800 \mathrm{~m} / \mathrm{s}$. This scenario has been chosen to provide a fair comparison with the pulse-like case/scenarios, as discussed in the following sections.
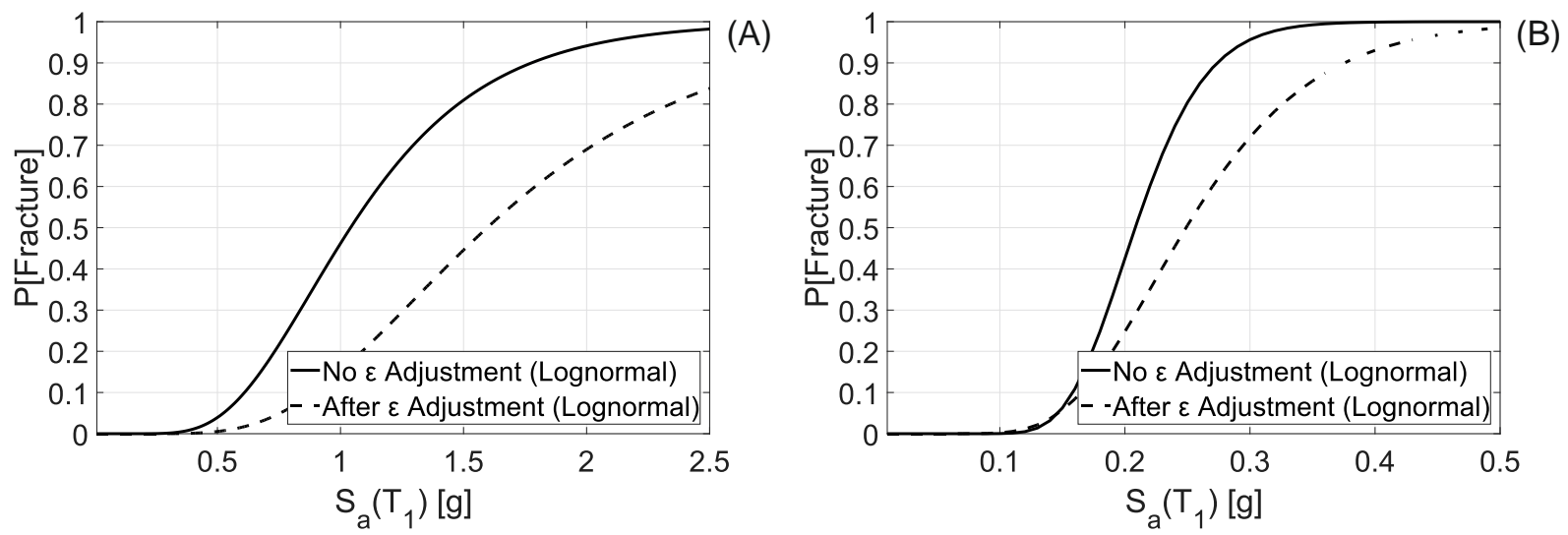

Figure 3 Examples of $\varepsilon$ adjustment for the fracture fragility in the case of far-field ground motions for (A) 4story (splice \#1); and (B) 20-story (splice \#2) WSMRF models

\subsection{Effect of Velocity Pulse on Fracture Analysis}

For the near-fault, pulse-like ground motions, the fracture fragility/risk assessment procedure is modified, as described below, such that the probability of fracture depends both on $S_{a}$ and the pulse period of the record, $T_{p}$. As in Champion and Liel ${ }^{[12]}$, it is observed in this study that, in contrast with the far-field ground motions, the scaling of pulse-like records does not introduce significant biases on the fracture fragility assessment if both pulse period and spectral acceleration are considered to represent the spectral shape of the considered records. In fact, the detected $T_{p}$ value for each near-fault ground motion shows a significant effect on the seismic fracture of pre-Northridge WCSs. Therefore, various group of pulse-like ground motions with different $T_{p}$ values can be considered to investigate the influence of $T_{p}$ and to reduce the effect of $\varepsilon$ on the fracture fragility estimates.

In particular, it has shown by various authors (e.g., Alavi and Krawinkler ${ }^{[37]}$; Baker and Cornell ${ }^{[31]}$; Champion and Liel $^{[12]}$; Tzimas et al. ${ }^{[13]}$ ) that the ratio of $T_{p}$ to $T_{1}$ (i.e., the fundamental period of a structure) has a critical effect on the seismic performance of buildings subjected to pulse-like records. Figure 4 plots this ratio (i.e., $T_{p} / T_{1}$ for each pulse-like record in the considered dataset) versus the associated fracture $S_{a}\left(T_{1}\right)$ (as defined above) for the 4-story and 20-story steel case-study frames, respectively. The fracture $S_{a}\left(T_{1}\right)$ of each pulse-like record is obtained from the corresponding IDA results by interpolating between the $S_{a}$ levels within which the estimated $\sigma_{D}$ exceeds $\sigma_{C}$. A larger value of fracture $S_{a}\left(T_{1}\right)$ implies that the ground motion has to be scaled to a higher $S_{a}$ level before fracture occurs (note that Figure 4 shows scaled records already). Moreover, following the approach of Champion and Liel ${ }^{[12]}$, the moving average of the empirical data is also plotted in Figure 4. This is computed by averaging the point of interest with five previous and subsequent data points (i.e., 11 data points in total). Based on the shape of moving average curve, the dependence of fracture $S_{a}\left(T_{1}\right)$ values resulting from varying $T_{p}$ values can be observed.

According to the moving average curves in Figure 4, the highest values of fracture $S_{a}\left(T_{1}\right)$ (for both WSMRF models) are obtained in the region where the pulse period $\left(T_{p}\right)$ is approximately equal to (or slightly higher than) the fundamental period of structure $\left(T_{1}\right)$. This observation indicates that the frame is least susceptible to seismic fracture when $T_{p}$ is around $T_{1}$, which is inconsistent with the response of linear-elastic system. However, this may be explained as follows: (1) when $T_{p}<T_{1}$, the pulse period may coincide with higher modes (particularly for taller buildings) and cause a traveling wave effect over the height of the building ${ }^{[38]}$, resulting in large displacement and 
axial force/stress demands in the upper stories; (2) when $T_{p}>T_{1}$, the building's effective fundamental period will elongate as damage accumulates, particularly in the case of ductile structures. Accordingly, ground-motion pulses with $T_{p}>T_{1}$ may be the most damaging. Obviously, records with $T_{p} \gg T_{1}$ behave in a similar way to ordinary records as the pulse period is far away from the building's most relevant frequencies. The first effect is especially evident in the case of the 20-story model (where, the smallest $S_{a}$ values are found in Figure 4B), causing an increase of the WCS stress demands for pulse-like records characterized by $T_{p}<T_{1}$. Similarly, the third effect is again especially evident in the case of the 20-story model, where the fracture $S_{a}\left(T_{1}\right)$ value tend to the far-field median fracture when $T_{p} \gg T_{1}$ (in addition, for this case-study frame, very limited period elongation is observed in general, as discussed in Song et al..$\left.^{[8]}\right)$.

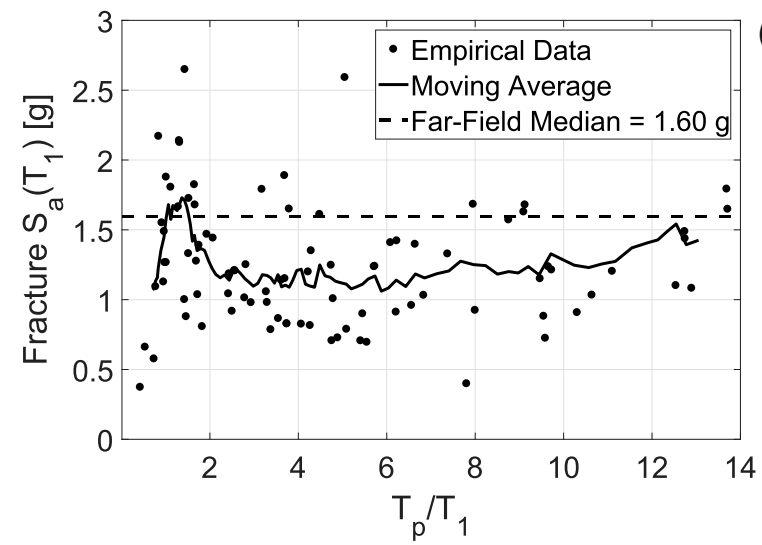

(A)

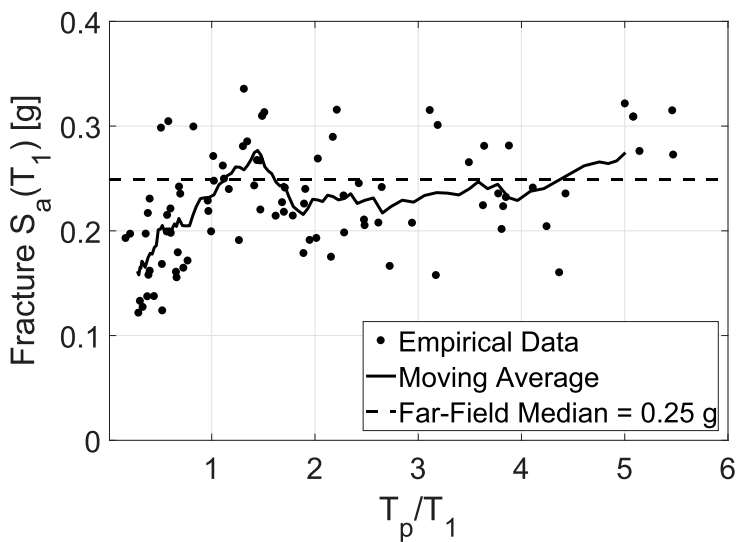

Figure 4 Relationship between fracture $S_{a}\left(T_{1}\right)$ and $T_{p} / T_{1}$ ratio for the 91 pulse-like records for (A) 4-story (splice \#1); and (B) 20-story (splice \#2) WSMRF models

These findings (in terms of the observed trend of fracture $S_{a}\left(T_{1}\right)$ vs $T_{p} / T_{1}$, as well as the shape of the moving average curves) are consistent with those by Champion and Liel ${ }^{[12]}$ for the collapse capacity (and associated collapse $S_{a}\left(T_{1}\right)$ values) of case-study reinforced concrete structures with various elastic/inelastic characteristics. However, larger differences (in terms of $S_{a}$ values) between the peak and valley of the moving average curves are generally found in the seismic collapse assessment with respect to the fracture evaluation carried out in this study. This may be attributed to the fact that the inelastic responses and elongation of the effective building period are more severe for a structure near collapse, while the fracture limit state in a given WCS connection is well below the intensity values corresponding collapse.

For comparison, the median values of fracture fragilities for both WSMRF models subjected to the far-field ordinary ground motion set (see Figure 3, they have been adjusted for $\varepsilon$ ) are depicted as horizontal dashed line in Figure 4. More considerable deviation between the far-field fracture $S_{a}\left(T_{1}\right)$ and the moving average curve is observed in Figure 4A (for splice \#1 in 4-story frame), comparing to Figure 4B (for splice \#2 in 20-story frame). This may be due to the significant increase in the stress demands in splice \#1 (far below its fracture capacity when subjected to the farfield ground motion set) because of pulse-like ground motions. These may cause seismic fracture at relatively lower $S_{a}$ levels (far below the far-field median level $-1.6 \mathrm{~g}$ ). On the contrary, the high stress demands in splice \#2 (when subjected to only far-field ground motions) are already comparable to its fracture capacity at low $S_{a}$ level (i.e., 0.25 $\mathrm{g}$, making the decrease in fracture $S_{a}\left(T_{1}\right)$ resulting from the forward directivity effects less significant. 


\section{FRACTURE RISK ASSESSMENT INCLUDING NEAR-FAULT DIRECTIVITY}

\subsection{Fracture Fragility Functions and Near-Source Probabilistic Seismic Hazard Analysis}

As discussed in Section 3, fracture fragility of pre-Northridge WCSs at a near-fault site depends on both $S_{a}$ and the occurrence of a velocity pulse (with its associated $T_{p}$ ). By using the total probability theorem, the probability of fracture (recall the fracture criterion, i.e., $\sigma_{D}>\sigma_{C}$ ) incorporating the effects of near-fault directivity, $P\left[\right.$ Fracture $\left.\mid S_{a}=x\right]$, for a given $S_{a}$ value of $x$, can be expressed as:

$P\left[\right.$ Fracture $\left.\mid S_{a}=x\right]=P\left[\right.$ Fracture $\mid S_{a}=x$, Pulse $] \cdot P\left[\right.$ Pulse $\left.\mid S_{a}=x\right]+P\left[\right.$ Fracture $\mid S_{a}=x$, No Pulse $] \cdot P\left[\right.$ No Pulse $\left.\mid S_{a}=x\right]$

The expression $P\left[\right.$ Fracture $\mid S_{a}=x$, No Pulse $]$ is the probability of fracture for ordinary records (when no pulse occurs), and can be determined directly from the fracture fragility curves derived for far-field ordinary ground motions (after the adjustment for $\varepsilon$, Section 3.1). The probability of fracture for pulse-like ground motions, $P\left[\right.$ Fracture $\mid S_{a}=x$, Pulse], depends on the pulse period and the corresponding distribution of pulse periods at a specific $S_{a}$ level of $x$ :

$P\left[\right.$ Fracture $\mid S_{a}=x$, Pulse $]=\sum_{i=1}^{\text {All } T_{p}} P\left[\right.$ Fracture $\mid T_{p}=t_{i}, S_{a}=x$, Pulse $] \cdot P\left[T_{p}=t_{i} \mid S_{a}=x\right.$, Pulse $]$

The probability of fracture for each given $T_{p}$ value, $P\left[\right.$ Fracture $\mid T_{p}=t_{i}, S_{a}=x$, Pulse $]$, is obtained from the relevant moving average curve plotted for each case-study frame (i.e., Figure 4, Section 3.2). The values determined from the curve are assumed to represent the median (lognormal mean) of the fracture $S_{a}\left(T_{1}\right)$ as a function of $T_{p}$. Then, a lognormal distribution can be defined to compute the probability of fracture for the given $T_{p}$ and $S_{a}$. The lognormal standard deviation is assumed to be equal to the corresponding $\beta$ estimated from IDA results for $P\left[\right.$ Fracture $\mid S_{a}=x$, No Pulse] (after the adjustment of $\varepsilon$ and an additional $10 \%$ increase due to the fracture capacity uncertainty, as discussed in Section 3), i.e., $\beta=0.46$ for splice \#1 (4-story frame); and $\beta=0.32$ for splice \#2 (20story frame).

In order to determine the other terms in Eqs. (1) and (2), near-source probabilistic seismic hazard analysis (NS-PSHA, e.g., Iervolino and Cornell ${ }^{[4]}$; Shahi and Baker ${ }^{[1]}$; Tothong et al. ${ }^{[39]}$ ) should be performed. NS-PSHA can be used to compute the mean annual frequency (MAF) of exceeding a spectral intensity value (denoted as $\lambda_{S_{a}>x}$ ), accounting for potential near-fault directivity. For a single seismic fault, $\lambda_{S_{a}>x}$ is generally defined as:

$\lambda_{S_{a}>x}=v \iint_{m} \int_{z} P\left[S_{a}>x \mid m, r, z\right] \cdot f_{M, R, Z}(m, r, z) d m d r d z$

where, $v$ is the mean annual rate of earthquake occurrence on the fault, $M$ is the earthquake (moment) magnitude, $R$ is the site-to-source distance, $Z$ defines the site-to-source geometry, and $f_{M, R, Z}$ is the joint probability density function of $M, R$ and $Z$. The term $P\left[S_{a}>x \mid m, r, z\right]$ is the probability that a specific $S_{a}$ value $(=x)$ is exceeded, given an earthquake of magnitude $m$ at distance $r$ and site-to-source geometry $z$. It depends on the probability of pulse occurrence, the distribution of possible pulse periods, and the peculiar spectral shape caused by the pulse.

In this study, the empirical model of Iervolino and Cornell ${ }^{[4]}$ is selected to compute the probability of a pulse occurring, $P[$ Pulse]. In the case of a SS fault rupture, it depends only on three geometrical parameters as (1) the site-to-source 
distance, $R$; (2) the distance from the epicenter to the site measured along the rupture direction, $s$; and (3) the angle between the fault strike and the path from epicenter to the site, $\theta$ :

$P[$ Pulse $]=\frac{e^{0.859-0.111 R+0.019 s-0.044 \theta}}{1+e^{0.859-0.111 R+0.019 s-0.044 \theta}}$

The pulse period distribution model employed here is that proposed by Chioccarelli and Iervolino ${ }^{[5]}$, and is given in Eq. (5) below:

$\ln T_{p}=-6.19+1.07 M$

Eq. (5) expresses the natural logarithm of $T_{p}$ as a function of the earthquake moment magnitude $(M)$ with a standard deviation of the residuals of 0.59 , which is relatively large, possibly due to the impact of other perturbations (e.g., site or propagation) on the prediction of the pulse period ${ }^{[40]}$.

To capture the spectral shape induced by the pulse, a modifying factor suggested in Baker ${ }^{[41]}$, which has been proved as generally useful to simulate pulse-like effects (e.g., Chioccarelli and Iervolino ${ }^{[40]}$ ), is applied to the original GMM used in this study (i.e., Boore and Atkinson ${ }^{[36]}$ ), such that:

$\overline{\ln \left(S_{a}(T)\right)}=\ln \left(S_{a}(T)\right)+e^{-\left(\ln \left(T / T_{p}\right)\right)^{2}}$

where, $\ln \left(S_{a}(T)\right)$ is the original GMM of Boore and Atkinson ${ }^{[36]}$ and $\overline{\ln \left(S_{a}(T)\right)}$ is the modified GMM to account for the pulse-like features in ground motion. The factor of $e^{-\left(\ln \left(T / T_{p}\right)\right)^{2}}$ models a bump in the elastic spectral shape with a maximum at $T=T_{p}$; this semi-empirically calibrated factor represents the systematic deviation of spectral ordinates of pulse-like signals to their ordinary counterparts, around the pulse period.

To allow the combination with the fracture fragility functions described in Eq. (1), the NS-PSHA should be represented as $\lambda_{S_{a}=x}$, rather than $\lambda_{S_{a}>x}$, because the MAF of a given $S_{a}(=x)$ is of interest. Once $\lambda_{S_{a}=x}$ has been calculated, hazard disaggregation can be performed to compute the probability of pulse occurrence at the $S_{a}$ level:

$P\left[\right.$ Pulse $\left.\mid S_{a}=x\right]=\frac{\lambda_{S_{a}=x, \text { Pulse }}}{\lambda_{S_{a}=x}}$

According to Eq. (7), $P\left[\right.$ Pulse $\left.\mid S_{a}=x\right]$ is defined as the ratio of the MAF of $S_{a}=x$ when only pulse-like records are considered to the total MAF of $S_{a}=x$. Note that this hazard disaggregation is required for all the considered $S_{a}$ levels. Following this, the term $P\left[\right.$ No Pulse $\left.\mid S_{a}=x\right]$ is given as:

$P\left[\right.$ No Pulse $\left.\mid S_{a}=x\right]=1-P\left[\right.$ Pulse $\left.\mid S_{a}=x\right]$

Similarly, the term $P\left[T_{p}=t_{i} \mid S_{a}=x\right.$, Pulse $]$ (i.e., the marginal disaggregation distribution of pulse period at each given $S_{a}$ level of interest) can also be computed by considering only the case of pulse occurrence ${ }^{[40]}$.

\subsection{Description of Near-Fault Sites}

In this study, a single characteristic M7 SS fault is considered to compare the seismic fracture risk of WCSs in WSMRFs located at near-fault sites and far-field sites. Based on median value of the Wells and Coppersmith magnitude-scaling relation ${ }^{[42]}$, the length of this fault is assumed equal to $42 \mathrm{~km}$. The mean annual rate of earthquake occurrence on the fault (denoted as $v$ ) is assumed as 0.05 and the location of earthquake epicenters is uniformly 
distributed along the fault. As shown in Figure 5, six sites with site-to-source distance of 5, 10 and $15 \mathrm{~km}$ at the end (i.e., "end-of-fault" sites) and midpoint (i.e., "midfault" sites) of the fault line are considered. In principle, the earthquake rupture length and its position are random variables. However, similar to the applications discussed in Chioccarelli and Iervolino ${ }^{[43]}$, the simplifying hypothesis of using fixed rupture and position (i.e., equal to the assumed fault length) is applied in this study. As a result, a deterministic relationship between parameters of $R, S$ and $\theta$ (to compute $P$ [Pulse] of Eq. (4)), rupture/fault length and position, as well as the location of earthquake epicenter can be determined, according to Figure 5 and the assumptions made above. It is worth noting that the main focus of this study is on comparing the fracture fragility/risk of pre-Northridge WCSs (in WSMRFs) located in the near-fault sites and far-field sites, rather than to investigate NS-PSHA itself. This simplifying hypothesis made above are generally acceptable if a single magnitude seismic event is considered on the assumed fault. Following this, the uncertainties involved for the hazard computations could be simulated easily ${ }^{[13]}$.

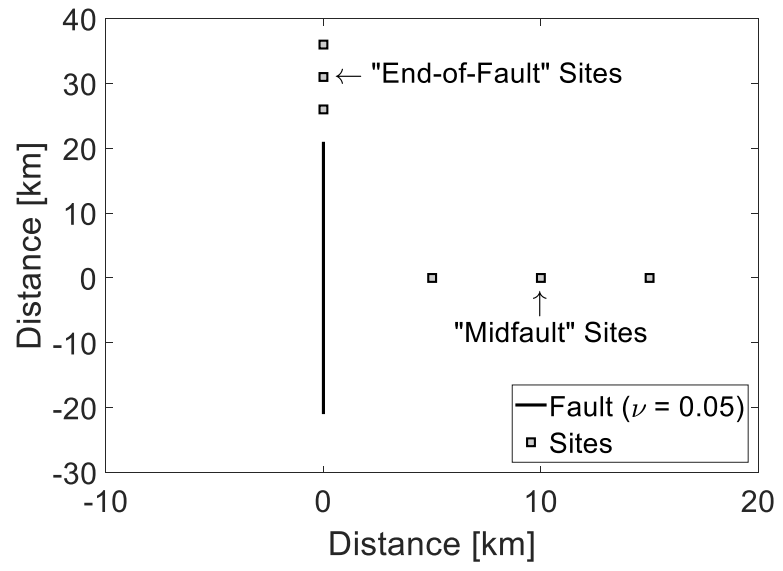

Figure 5 Locations of six representative near-fault sites considered in this study

Results of NS-PSHA for the 4-story frame $\left(T_{1}=0.94 \mathrm{~s}\right)$ and the 20 -story frame $\left(T_{1}=2.36 \mathrm{~s}\right)$ are shown in Figures $6 \mathrm{~A}$ and $6 \mathrm{~B}$, respectively. As expected, these computed seismic (site-specific) hazard curves indicate that larger earthquakes are more likely when the site-to-source distance decreases. The hazard disaggregation results in terms of the probability of pulse occurrence at each $S_{a}$ level (i.e., $P\left[\right.$ Pulse $\left.\mid S_{a}=x\right]$ ) for all the six considered sites are illustrated in Figures 6C and 6D, for the 4-story and the 20-story frames, respectively. It can be observed that (1) the probabilities of pulse occurring at end-of-fault sites are significantly higher than those at midfault sites; and (2) the effects of varying site-to-source distance on the pulse occurrence likelihood are significant at midfault sites, showing large separation among dashed lines (for midfault sites at 5, 10, and $15 \mathrm{~km}$ away from fault), while the differences of $P\left[\right.$ Pulse $\left.\mid S_{a}=x\right]$ values at three end-of-fault sites are limited, particularly at higher $S_{a}$ levels. Figures $6 \mathrm{E}$ and $6 \mathrm{~F}$ show typical distributions of pulse periods referring to specific $S_{a}$ levels (i.e., $P\left[T_{p}=t_{i} \mid S_{a}=x\right.$, Pulse $]$ ) for both case-study WSMRFs at the $5 \mathrm{~km}$ midfault site. The selected $S_{a}$ levels for 4 - and 20 -story frames are $1 \mathrm{~g}$ and $0.2 \mathrm{~g}$, as indicated in the corresponding figures.

The NS-PSHA results, such as these shown in Figure 6, for the six case-study sites (Figure 5) offer the possibility to investigate the influence of both site-to-source geometry and structural properties on fracture risk of pre-Northridge WCSs in near-fault regions.

\subsection{Results and Discussion}

The IDA results (Section 3) for the case-study WSMRFs are used to assess the potential increase in seismic fracture fragility/risk of WCSs due to near-fault directivity and pulse effects. Applying the probabilistic methodology described in Section 4.1 above (to include the effects of pulse-like ground motions), the fracture fragility curves for both frames at all six near-fault sites (Section 4.2) are developed, i.e., Figure 7 for splice \#1 in the 4-story frame and Figure 8 for splice \#2 in the 20-story frame, respectively. The corresponding median fracture fragility results are listed 
in Table 1. These results highlight the effect of site-to-source geometry and building parameters on the fractural fragility assessment of pre-Northridge WCSs in the near-fault region.

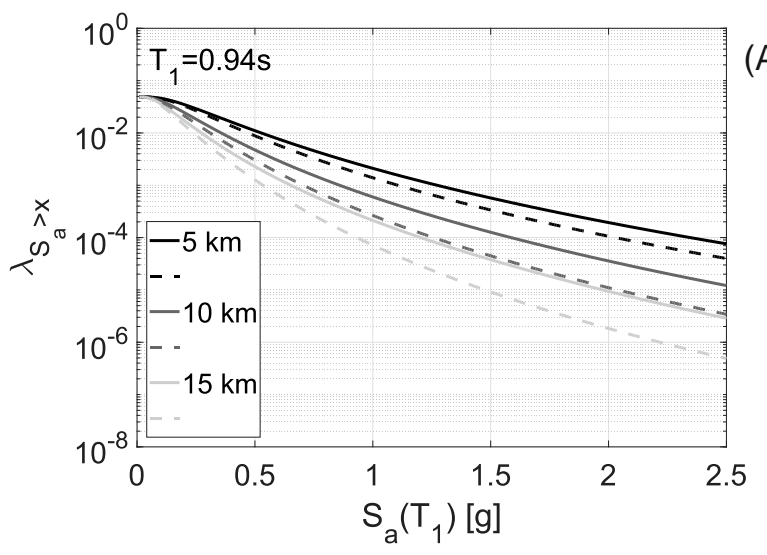

(A)
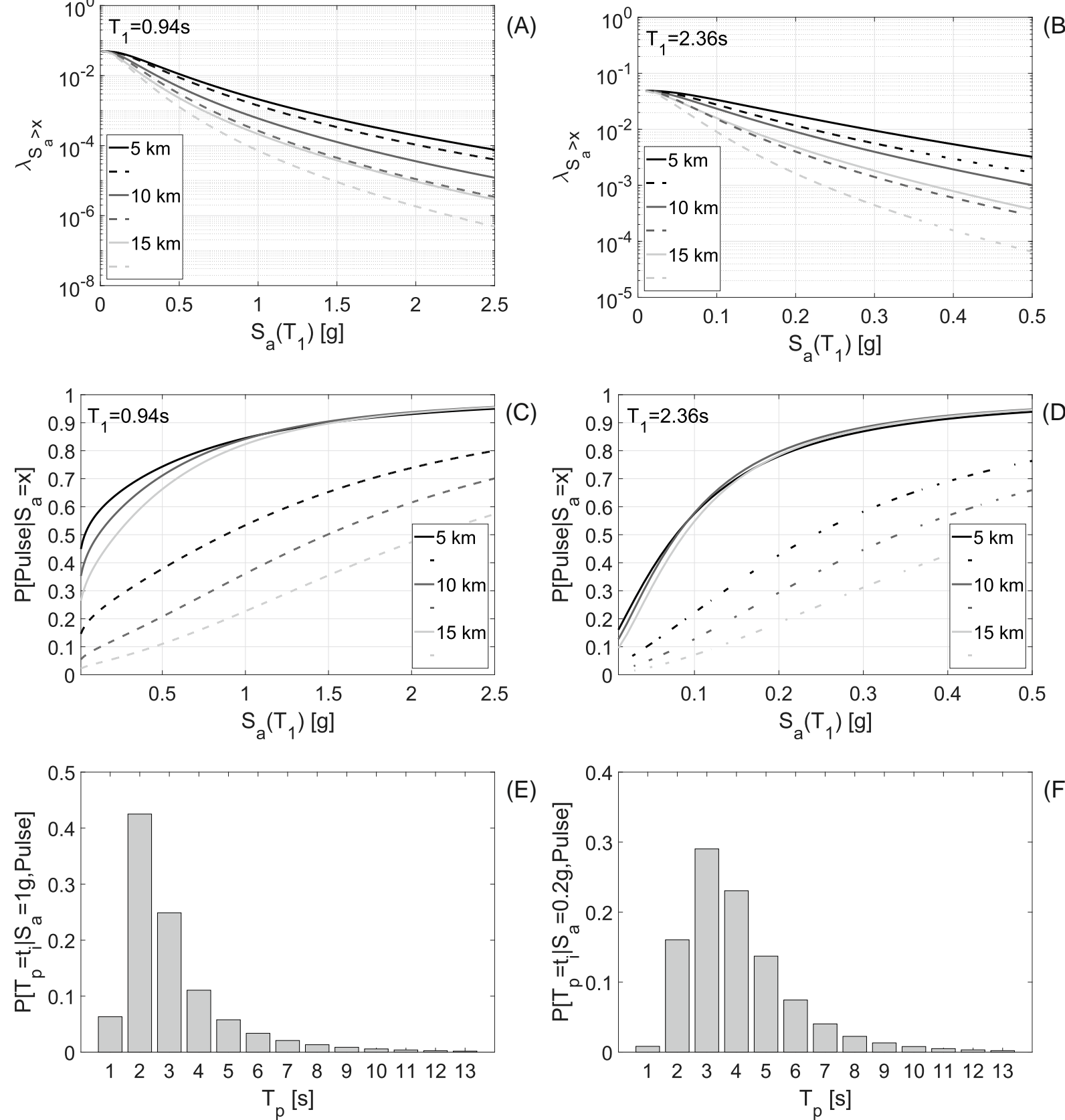

(F)

Figure 6 Results of NS-PSHA for the 4-story frame ( $\left.T_{1}=0.94 \mathrm{~s}\right)$ and the 20-story frame $\left(T_{1}=2.36 \mathrm{~s}\right)$, showing seismic hazard curves for (A) 4-story frame and (B) 20-story frame; probabilities of pulse occurrence, at midfault (dashed lines) and end-of-fault (solid lines) sites for (C) 4-story frame and (D) 20-story frame; and hazard disaggregation results of a typical pulse period distribution for (E) one hazard level of $S_{a}=1 \mathrm{~g}$, for 4-story frame and (F) one hazard level of $S_{a}=0.2 \mathrm{~g}$ for 20-story frame, at the $5 \mathrm{~km}$ midfault site 

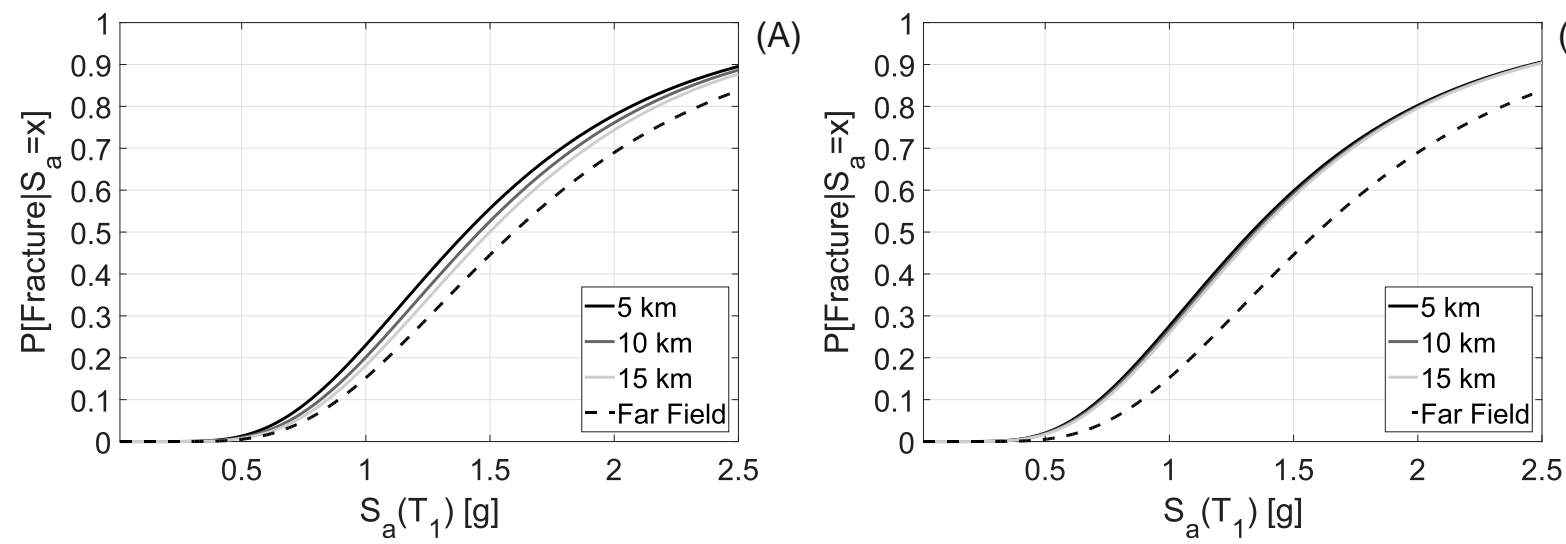

(B)

Figure 7 Fracture fragility functions for 4-story frame (splice \#1) at (A) three different midfault and (B) end-offault sites, with far-field fragility curves

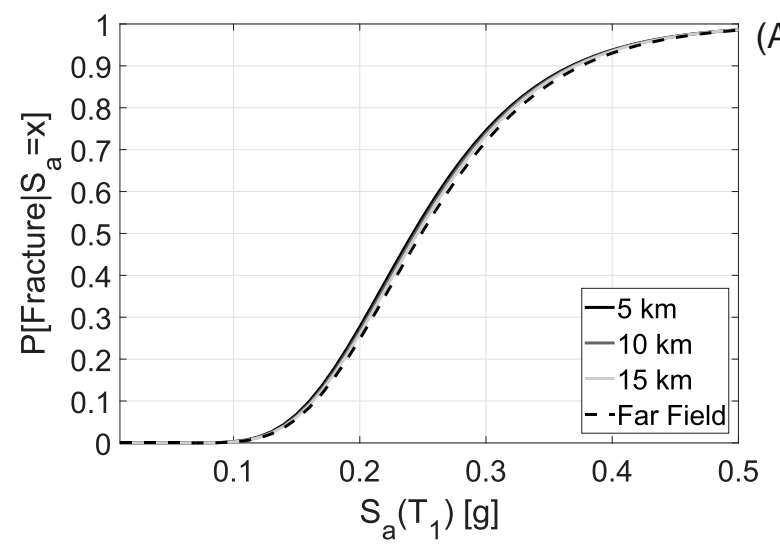

(A)

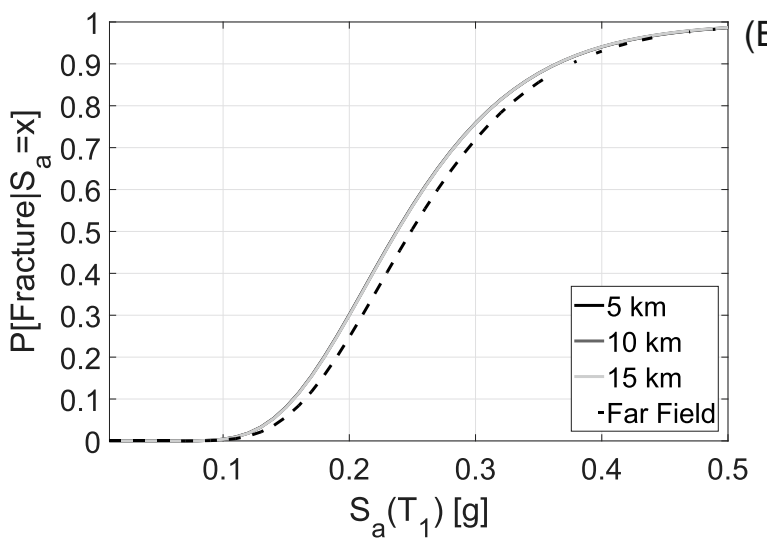

(B)

Figure 8 Fracture fragility functions for 20-story frame (splice \#2) at (A) three different midfault and (B) endof-fault sites, with far-field fragility curves

Table 1 Median fracture fragility results [g] for splice \#1 (4-story frame) and splice \#2 (20-story frame) at six designated near-fault sites

\begin{tabular}{ccccccc}
\hline \multirow{2}{*}{ Frame (WCS) } & \multicolumn{3}{c}{ Midfault sites } & \multicolumn{3}{c}{ End-of-fault sites } \\
\cline { 2 - 6 } & $5 \mathrm{~km}$ & $10 \mathrm{~km}$ & $15 \mathrm{~km}$ & $5 \mathrm{~km}$ & $10 \mathrm{~km}$ & $15 \mathrm{~km}$ \\
\hline 4-story (splice \#1) & 1.405 & 1.457 & 1.499 & 1.331 & 1.346 & 1.356 \\
20-story (splice \#2) & 0.242 & 0.244 & 0.246 & 0.237 & 0.237 & 0.238 \\
\hline
\end{tabular}

Looking at the 4-story frame (i.e., the mid-rise WSMRF considered in this study), the impact of site-to-source distance on the probability of fracture (i.e., fracture fragility for the selected WCS, splice \#1) is illustrated in Figure 7. As expected, higher probabilities of fracture are observed for sites closer to the fault due to the increase in pulse probability. The far-field fragility curves are also plotted in the same figures for comparison. For this particular frame located at the $5 \mathrm{~km}$ end-of fault site, the near-fault directivity and pulse effects can reduce the median fragility of more than $16 \%$ from the median of the associated far-field fracture fragility curve. It is also observed that the near-fault fracture fragility curves tend to approach the far-field curve with the increase of distance from the fault rupture. As demonstrated by Champion and Liel ${ }^{[12]}$, this distance at which the near-fault curve reaches the far-field one mainly depends on the fundamental period and the nonlinear properties of the assessed building. The large separations between fracture fragility curves at the $15 \mathrm{~km}$ (midfault and end-of-fault) sites and the far-field ones indicate that, for this 4-story frame at $15 \mathrm{~km}$ sites, there are still relatively high pulse probabilities at the $S_{a}$ levels large enough to cause fracture. In addition, according to Figure 7 and Table 1, the differences of the fracture fragility curves and their corresponding median fracture fragility values at three end-of-fault sites are moderate, because, referring to Figure 6C, the pulse probabilities (for each $S_{a}$ level) at these three sites are similar. Conversely, considerable separations 
can be found in the fracture fragility curves (and the corresponding median values) at midfault sites, due to the larger differences in pulse probabilities, such that shown in Figure 6C. Moreover, because of the significantly higher pulse probabilities computed at end-of-fault sites, their fracture fragility curves are plotted at right-hand side to those for midfault sites. This is also confirmed in Table 1 that the predicted median fragility values for end-of-fault sites are smaller.

In general, similar trends are observed for the fracture fragility curves of the 20-story steel frame (i.e., the representative high-rise WSMRF in this study) at near-fault sites. However, only negligible differences between the various near-fault fragility curves are shown in Figure 8, for both midfault and end-of-fault sites. This finding is also clear when comparing the median fracture fragilities listed in Table 1. This may be attributable to two issues: (1) the significantly high stress demands of 20-story frame model at low $S_{a}$ level (owing to overturning for instance) and relative low fracture capacity of splice \#2, making it very susceptible to fracture, even at the farthest near-fault sites located $15 \mathrm{~km}$ away from the assumed scenario fault and the far-field site (comparing to the $5 \mathrm{~km}$ sites) considered in this study. This finding can be also confirmed when looking at Figure 4B, in which the fracture $S_{a}\left(T_{1}\right)$ values obtained from the moving average curve are small (i.e., roughly between $0.16 \mathrm{~g}$ and $0.27 \mathrm{~g}$ ) and close to the median of far-field fracture fragility curve (i.e., $0.25 \mathrm{~g}$ ). It seems that the fracture fragility curves constructed for splice \#2 (in 20-story frame) are largely controlled by the fracture criterion itself (i.e., the stress demands of WCS at $15 \mathrm{~km}$ sites/farfield site are large enough to cause the fracture failure), rather than the increase in $\sigma_{D}$ due to the forward directivity effects and the decrease of site-to-source distance; (2) the magnitude of the near-fault pulse effects on fracture fragility depends on both the fundamental period of the structure $\left(T_{1}\right)$ and the distinct pulse period distributions ${ }^{[12]}$. Given a single characteristic M7 earthquake (as assumed in this study), the typical range of $T_{p}$ is between 2 and $6.6 \mathrm{~s}$ (calculated from the model of Eq. (5) with its uncertainty, also see Figure 6F as an example), with a modal value of about $3 \mathrm{~s}$. In the case of 20-story frame with $T_{1}=2.36 \mathrm{~s}$, the structural response may be dominated by pulses with $T_{p} / T_{1}$ ratio between 1 and 3 , with little impact from the higher-mode region of response (where the smallest fracture $S_{a}\left(T_{1}\right)$ values exist). Referring to Figure $4 \mathrm{~B}$, the fracture $S_{a}\left(T_{1}\right)$ values vary around (and close to) the far-field median. These two issues result in the similar probabilities of fracture computed for the pulse-like and far-field ground motions, and finally lead to almost the same results for near-fault fracture fragility curves at different sites (according to Eqs. (1) and (2)). It is worth noting that the slight differences in median fracture fragility values (at six near-fault sites) are mainly due to the various pulse probabilities for these sites (Figure 6D).

Furthermore, two additional metrics, i.e., (1) the probability of fracture in 50 years (the typical design life of a generic building, $P$ [Fracture in 50 years]) and (2) the return period for fracture (in years), for each selected WCS are also calculated to directly show the fracture risk of WCSs at near-fault sites. The former is determined by assuming a Poisson distribution of earthquake occurrences as follow:

$P[$ Fracture in 50 years $]=1-e^{-\lambda[\text { fracture }] \cdot t}$

where, $t$ is the time in years and $\lambda[$ Fracture] is the MAF of fracture. The calculation of $\lambda[$ Fracture] is conducted by probabilistic seismic demand analysis (PSDA), as shown in Galasso et al. ${ }^{[7]}$. In this study, PSDA combines a seismic hazard curve in terms of $S_{a}$ for each designated site, computed through NS-PSHA, with the fragility results from IDA (i.e., the probability of fracture given a level of $S_{a}, P\left[\right.$ Fracture $\left.\mid S_{a}=x_{i}\right]$ of Eq. (1)). This PSDA approach is again an application of the total probability theorem. Adapted to the specific situation of WCSs, it can be converted into a discrete summation (for numerical calculation), expressed as:

$$
\lambda[\text { Fracture }]=\sum_{\text {all } x_{i}} P\left[\text { Fracture } \mid S_{a}=x_{i}\right] \cdot\left|\Delta \lambda_{S_{a}}\left(x_{i}\right)\right|
$$

More specifically, $P\left[\right.$ Fracture $\left.\mid S_{a}=x_{i}\right]$ can be obtained from the site-specific fracture fragility curves (i.e., Figures

7 and 8), and $\left|\Delta \lambda_{S_{a}}\left(x_{i}\right)\right|$ is the MAF of a given $S_{a}$ value $\left(=x_{i}\right)$. It can be approximately computed from the MAF of 
exceedance of each $S_{a}=x_{i}$ (i.e., $\lambda_{S_{a}>x}$ of Eq. (3)) and the corresponding site-specific ground motion hazard curve (i.e., Figures 6A and 6B), in the form that $\left|\Delta \lambda_{S_{a}}\left(x_{i}\right)\right|=\left|\lambda_{S_{a}>x}\left(x_{i}\right)-\lambda_{S_{a}>x}\left(x_{i+1}\right)\right|$. Following this, the latter metric of fracture risk (i.e., the return period for fracture) can be easily computed as the reciprocal of $\lambda$ [Fracture]. The results of such calculations for both splices \#1 and \#2 at all the six (midfault/end-of-fault) sites are presented in Table 2.

Table 2 Comparison of two metrics of fracture risk for splice \#1 (4-story frame) and splice \#2 (20-story frame) at six designated near-fault sites: probability of fracture in 50 years [\%] and return period for fracture (in years)

\begin{tabular}{cccccccc}
\hline \multirow{2}{*}{ Frame (WCS) } & \multirow{2}{*}{ Metric } & \multicolumn{3}{c}{ Midfault sites } & \multicolumn{3}{c}{ End-of-fault sites } \\
\cline { 3 - 7 } & & $5 \mathrm{~km}$ & $10 \mathrm{~km}$ & $15 \mathrm{~km}$ & $5 \mathrm{~km}$ & $10 \mathrm{~km}$ & $15 \mathrm{~km}$ \\
\hline 4-story & $P$ [Fracture in 50 years] [\%] & 5.26 & 1.15 & 0.35 & 8.73 & 3.03 & 1.24 \\
(splice \#1) & Return period for fracture [years] & 926 & 4340 & 14417 & 548 & 1627 & 3991 \\
20-story & $P$ [Fracture in 50 years] [\%] & 30.49 & 12.54 & 5.49 & 41.87 & 26.21 & 15.67 \\
(splice \#2) & Return period for fracture [years] & 137 & 373 & 886 & 92 & 165 & 293 \\
\hline
\end{tabular}

As expected, a clear trend can be observed: the fracture risk of these two selected pre-Northridge WCSs in the 4- and 20-story WSMRFs at near-fault sites increases when the site-to-source distance decrease, due to near-fault directivity and pulse effects. For splice \#1 (4-story frame), the computed $P$ [Fracture in 50 years] values are $4.67 \%$ and $7.93 \%$ at the closest (i.e., $5 \mathrm{~km}$ ) midfault and end-of-fault sites, respectively. They are roughly 17 and eight times higher than their counterparts at the most distant near-fault sites (i.e., $15 \mathrm{~km}$ ). Similar results are found for splice \#2 in the 20story frame, with a six- and a three-time rise in terms of fracture probabilities in 50 years for the $5-\mathrm{km}$ and $15-\mathrm{km}$ sites located at the midpoint and the end of the fault line, respectively. Moreover, Table 2 also indicates the decreased return periods (in years) with sites approaching the fault rupture. The return periods for fracture at $5-\mathrm{km}$ sites vary by a factor of about $1 / 18$ to $1 / 3$ over those estimated for $15-\mathrm{km}$ sites.

Comparing the fracture risk at each of the equidistant midfault and end-of-fault sites for the same frame, the larger values of the fracture probability in 50 years and the lower values of the return period for fracture are found at the end-of-fault sites. This is mainly because the probabilities of pulse-like ground motions occurrence, which depend on the site-to-source geometry, are higher at the end-of-fault sites (refer to Figures 6C and 6D). The rupture directivity is towards these sites, in terms of the site-to-source geometry considered in this study ${ }^{[1]}$. In addition, it is also observed that the fracture risk is largely affected by the effects caused by the site-to-source distance, compared with the relative position of the site with respect to the fault axis (i.e., midfault or end-of-fault). It seems that the distance to the fault rupture (for a single strike-slip fault) is more critical than the other parameters in site-to-source geometry to assess the fracture risk of WCSs.

According to Table 2, it is also interesting to point out that the increase in the fracture risk (with the decrease of siteto-source distance) of splice \#2 (20-story frame) is also significant, although the fracture fragility of 20-story frame derived from three near-fault locations (at either midfault or end-of-fault sites) are very similar. This is mainly because the fracture risk, represented by MAF of fracture (Eq. (10)), is not only a function of fracture fragility, but is also related to the MAF of exceeding for each $S_{a}$ level (see site-specific seismic hazard curves for the 20-story WSMRF, i.e., Figure 6B). Moreover, the return periods for fracture of splice \#2 at all the near-fault sites (except for the 15-km midfault site) are unacceptably low, comparing to the return period of the design earthquake (i.e., 475 years). This inspection reveals that WCSs in the 20-story frame (or some other high-rise WSMRFs) may be at an extremely high risk of fracture, due to a combination of large fracture probabilities and high MAF of exceedance at low $S_{a}$ levels. As emphasized by Galasso et al. ${ }^{[7]}$, the fracture of a WCS does not necessarily lead to collapse or safety loss, since it also depends upon several other factors, such as building configuration (i.e., redundancy). However, based on the general presumption that WCS fracture is highly undesirable because it is likely to damage the crucial load-carrying element in a structure (i.e., column), the findings may warrant a serious and urgent consideration of retrofit strategies for pre-Northridge WCSs installed in mid- to high-rise WSMRFs in any near-fault regions.

\section{CONCLUDING REMARKS}

This study investigated the effects of near-fault directivity on fracture risk of WCSs, through nonlinear dynamic analysis of two case-study frames (i.e., 4-story and 20-story WSMRFs featuring WCSs). A suite of 91 near-fault, 
pulse-like ground motions (with varying $T_{p}$ ) and a set of 21 far-field, ordinary earthquake records were used to perform IDA. The results of the IDA were then combined with NS-PSHA to evaluate the fracture risk including pulse effects at six designated near-fault sites for a case-study scenario fault rupture.

Based on IDA results for the pulse-like records, the seismic fracture of WCSs in the near-fault region is mainly controlled by the ratio between the pulse period of a given ground motion and the fundamental period of the assessed structure (i.e., $T_{p} / T_{1}$ ). Certain pulse-like ground motions, characterized by $T_{p}$ values significantly different than $T_{1}$

can cause a considerable decrease in terms of fracture $S_{a}\left(T_{1}\right)$ relative to the results obtained from the ordinary records, and therefore, are more critical for fracture risk assessment in near-fault regions.

The probabilistic fracture risk assessment results, in terms of the fragility curves, the probability of fracture in 50 years and the return period for fracture (derived from MAF of fracture), indicate that the fracture risk experiences a considerable increase, when the near-fault directivity and pulse effects are properly considered in the NS-PSHA and the structural response simulation. More specifically, the fracture risk of WCS substantially increases as the site-tosource distance decreases. Moreover, considering any specific frame, the influence of the distance from fault rupture on the fracture risk is more significant to the effect caused by the relative site location to the fault axis. In particular, very high fracture susceptibility of splice \#2 in 20-story WSMRF is found in this study and indicated by significantly low return period for fracture ( $<475$ years for the return period of design earthquake). This highlights that the design of retrofitting strategies for pre-Northridge WCSs in high-rise steel structures located in near-fault regions is urgently needed.

The main limitations of this study are in the computation of the site-specific seismic hazard. Although the NS-PSHA models employed in this study explicitly considered the occurrence of velocity pulses, only a single scenario fault and one set of empirical models for NS-SPHA and GMM were used (rather than, for instance, the use of a logic-tree combination of different models/GMMs and multiple faults). As a result, while the main conceptual findings (e.g., the relative comparisons between the various metrics related to fracture risk and their observed trends with respect to the site-to-source geometry) would stand for different rupture scenarios, some variations in the absolute values of these results may be expected if other hazard characteristics would be explicitly modeled.

\section{ACKNOWLEDGEMENT}

The first author would like to acknowledge the financial support from China Scholarship Council (CSC, Grant number: 201608330227) and University College London (UCL) through a joint research scholarship.

\section{REFERENCES}

1. Shahi SK, Baker JW. An Empirically Calibrated Framework for Including the Effects of Near-Fault Directivity in Probabilistic Seismic Hazard Analysis. Bulletin of the Seismological Society of America 2011; 101(2): 742-755. DOI: 10.1785/0120100090.

2. Singh JP. Earthquake Ground Motions: Implications for Designing Structures and Reconciling Structural Damage. Earthquake Spectra 1985; 1(2): 239-270. DOI: 10.1193/1.1585264.

3. Somerville PG, Smith NF, Graves RW, Abrahamson NA. Modification of Empirical Strong Ground Motion Attenuation Relations to Include the Amplitude and Duration Effects of Rupture Directivity. Seismological Research Letters 1997; 68(1): 199-222. DOI: 10.1785/gssrl.68.1.199.

4. Iervolino I, Cornell CA. Probability of Occurrence of Velocity Pulses in Near-Source Ground Motions. Bulletin of the Seismological Society of America 2008; 98(5): 2262-2277. DOI: 10.1785/0120080033.

5. Chioccarelli E, Iervolino I. Near-source seismic demand and pulse-like records: A discussion for L'Aquila earthquake. Earthquake Engineering \& Structural Dynamics 2010; 13(9): 1039-1062. DOI: 10.1002/eqe.987.

6. Shaw SM, Stillmaker K, Kanvinde AM. Seismic response of partial-joint-penetration welded column splices in moment-resisting frames. Engineering Journal 2015; 52(2): 87-108.

7. Galasso C, Stillmaker K, Eltit C, Kanvinde A. Probabilistic demand and fragility assessment of welded column splices in steel moment frames. Earthquake Engineering \& Structural Dynamics 2015; 44(11): 1823-1840. DOI: 10.1002/eqe.2557. 
8. Song B, Galasso C, Kanvinde A. Advancing fracture fragility assessment of pre-Northridge welded column splices. Earthquake Engineering \& Structural Dynamics 2019: eqe.3228. DOI: 10.1002/eqe.3228.

9. Chi WM, Deierlein GG, Ingraffea A. Fracture Toughness Demands in Welded Beam-Column Moment Connections. Journal of Structural Engineering 2000; 126(1): 88-97. DOI: 10.1061/(ASCE)07339445(2000)126:1(88).

10. American Institute of Steel Construction (AISC). Seismic Provisions for Structural Steel Buildings (ANSI/AISC 341-16). Chicago, IL: American Institute of Steel Construction; 2016.

11. Bruneau M, Mahin SA. Ultimate Behavior of Heavy Steel Section Welded Splices and Design Implications. Journal of Structural Engineering 1990; 116(8): 2214-2235. DOI: 10.1061/(ASCE)07339445(1990)116:8(2214).

12. Champion C, Liel A. The effect of near-fault directivity on building seismic collapse risk. Earthquake Engineering \& Structural Dynamics 2012; 41(10): 1391-1409. DOI: 10.1002/eqe.1188.

13. Tzimas AS, Kamaris GS, Karavasilis TL, Galasso C. Collapse risk and residual drift performance of steel buildings using post-tensioned MRFs and viscous dampers in near-fault regions. Bulletin of Earthquake Engineering 2016; 14(6): 1643-1662. DOI: 10.1007/s10518-016-9898-3.

14. Mazzoni S, McKenna F, Scott MH, Fenves GL. Open System for Earthquake Engineering Simulation User Command-Language Manual. OpenSees version 2.0. Berkeley, CA: Pacific Earthquake Engineering Research Center, University of California, Berkeley; 2009.

15. Vamvatsikos D, Cornell CA. Incremental dynamic analysis. Earthquake Engineering \& Structural Dynamics 2002; 31(3): 491-514. DOI: 10.1002/eqe.141.

16. Stillmaker K, Kanvinde A, Galasso C. Fracture Mechanics-Based Design of Column Splices with Partial Joint Penetration Welds. Journal of Structural Engineering 2016; 142(2): 04015115. DOI: 10.1061/(ASCE)ST.1943-541X.0001380.

17. Gupta A, Krawinkler H. Seismic Demands for Performance Evaluation of Steel Moment Resisting Frame Structures. Technical Report No. 132 (SAC Task 5.4.3). Stanford, CA: John A. Blume Earthquake Engineering Center, Stanford University; 1999.

18. Shen J, Sabol TA, Akbas B, Sutchiewcharn N. Seismic Demand on Column Splices in Steel Moment Frames. Engineering Journal 2010; 47(4): 223-240.

19. American Institute of Steel Construction (AISC). Seismic Provisions for Structural Steel Buildings (AISC 341-10). Chicago, IL: American Institute of Steel Construction; 2010.

20. American Society of Civil Engineers (ASCE). Minimum Design Loads for Buildings and Other Structures (ASCE/SEI 7-05). Reston, VA: American Society of Civil Engineers; 2006.

21. Shaw SM. Seismic Performance of Partial Joint Penetration Welds in Special Moment Resisting Frames. $\mathrm{PhD}$ Thesis. University of California, Davis, 2013.

22. Spacone E, Filippou FC, Taucer FF. Fibre Beam-Column Model for Non-Linear Analysis of R/C Frames: Part I. Formulation. Earthquake Engineering \& Structural Dynamics 1996; 25(7): 711-725. DOI: 10.1002/(SICI)1096-9845(199607)25:7<711::AID-EQE576>3.0.CO;2-9.

23. Lignos DG, Krawinkler H, Whittaker AS. Prediction and validation of sidesway collapse of two scale models of a 4-story steel moment frame. Earthquake Engineering \& Structural Dynamics 2011; 40(7): 807825. DOI: $10.1002 /$ eqe. 1061.

24. Lignos DG, Krawinkler H. Deterioration Modeling of Steel Components in Support of Collapse Prediction of Steel Moment Frames under Earthquake Loading. Journal of Structural Engineering 2011; 137(11): 1291-1302. DOI: 10.1061/(ASCE)ST.1943-541X.0000376.

25. Stillmaker K, Lao X, Galasso C, Kanvinde A. Column splice fracture effects on the seismic performance of steel moment frames. Journal of Constructional Steel Research 2017; 137(2017): 93-101. DOI: 10.1016/j.jcsr.2017.06.013.

26. Baker JW. Quantitative Classification of Near-Fault Ground Motions Using Wavelet Analysis. Bulletin of the Seismological Society of America 2007; 97(5): 1486-1501. DOI: 10.1785/0120060255.

27. Mavroeidis GP. A Mathematical Representation of Near-Fault Ground Motions. Bulletin of the Seismological Society of America 2003; 93(3): 1099-1131. DOI: 10.1785/0120020100.

28. Somerville PG. Magnitude scaling of the near fault rupture directivity pulse. Physics of the Earth and Planetary Interiors 2003; 137(1-4): 201-212. DOI: 10.1016/S0031-9201(03)00015-3.

29. Shahi SK, Baker JW. An Efficient Algorithm to Identify Strong-Velocity Pulses in Multicomponent Ground Motions. Bulletin of the Seismological Society of America 2014; 104(5): 2456-2466. DOI:

$10.1785 / 0120130191$. 
30. Applied Technology Council (ATC). Quantification of Building Seismic Performance Factors (FEMA P695). Redwood City, CA: Federal Emergency Management Agency; 2009.

31. Baker JW, Cornell CA. Vector-valued intensity measures for pulse-like near-fault ground motions. Engineering Structures 2008; 30(4): 1048-1057. DOI: 10.1016/j.engstruct.2007.07.009.

32. Haselton CB, Baker JW, Liel AB, Deierlein GG. Accounting for Ground-Motion Spectral Shape Characteristics in Structural Collapse Assessment through an Adjustment for Epsilon. Journal of Structural Engineering 2011; 137(3): 332-344. DOI: 10.1061/(ASCE)ST.1943-541X.0000103.

33. Kazantzi AK, Vamvatsikos D. Intensity measure selection for vulnerability studies of building classes. Earthquake Engineering \& Structural Dynamics 2015; 44(15): 2677-2694. DOI: 10.1002/eqe.2603.

34. Luco N, Bazzurro P. Does amplitude scaling of ground motion records result in biased nonlinear structural drift responses? Earthquake Engineering \& Structural Dynamics 2007; 36(13): 1813-1835. DOI: 10.1002/eqe.695.

35. Baker JW, Cornell CA. A vector-valued ground motion intensity measure consisting of spectral acceleration and epsilon. Earthquake Engineering \& Structural Dynamics 2005; 34(10): 1193-1217. DOI: 10.1002/eqe.474.

36. Boore DM, Atkinson GM. Ground-Motion Prediction Equations for the Average Horizontal Component of PGA, PGV, and 5\%-Damped PSA at Spectral Periods between $0.01 \mathrm{~s}$ and 10.0 s. Earthquake Spectra 2008; 24(1): 99-138. DOI: 10.1193/1.2830434.

37. Alavi B, Krawinkler H. Behavior of moment-resisting frame structures subjected to near-fault ground motions. Earthquake Engineering \& Structural Dynamics 2004; 33(6): 687-706. DOI: 10.1002/eqe.369.

38. Iwan WD. Drift Spectrum: Measure of Demand for Earthquake Ground Motions. Journal of Structural Engineering 1997; 123(4): 397-404. DOI: 10.1061/(ASCE)0733-9445(1997)123:4(397).

39. Tothong P, Cornell CA, Baker JW. Explicit Directivity-Pulse Inclusion in Probabilistic Seismic Hazard Analysis. Earthquake Spectra 2007; 23(4): 867-891. DOI: 10.1193/1.2790487.

40. Chioccarelli E, Iervolino I. Near-source seismic hazard and design scenarios. Earthquake Engineering \& Structural Dynamics 2013; 42(4): 603-622. DOI: 10.1002/eqe.2232.

41. Baker JW. Identification of near-fault velocity pulses and prediction of resulting response spectra. Geotechnical Earthquake Engineering and Soil Dynamics IV, Sacramento, CA: 2008.

42. Wells DL, Coppersmith KJ. New empirical relationships among magnitude, rupture length, rupture width, rupture area, and surface displacement. Bulletin of the Seismological Society of America 1994; 84(4): 974 1002.

43. Chioccarelli E, Iervolino I. Sensitivity analysis of directivity effects on PSHA. Bollettino Di Geofisica Teorica e Applicata 2014; 55(1): 41-53. DOI: 10.4430/bgta0099. 